This is an electronic reprint of the original article. This reprint may differ from the original in pagination and typographic detail.

Author(s): Taipale, Sakari; Leopoldina, Fortunati

Title: $\quad$ Capturing Methodological Trends in Mobile Communication Studies

Year: $\quad 2014$

Version:

Please cite the original version:

Taipale, S., \& Leopoldina, F. (2014). Capturing Methodological Trends in Mobile Communication Studies. Information, Communication and Society, 17(5), 627-642. https://doi.org/10.1080/1369118X.2013.862562

All material supplied via JYX is protected by copyright and other intellectual property rights, and duplication or sale of all or part of any of the repository collections is not permitted, except that material may be duplicated by you for your research use or educational purposes in electronic or print form. You must obtain permission for any other use. Electronic or print copies may not be offered, whether for sale or otherwise to anyone who is not an authorised user. 


\section{Capturing Methodological Trends in Mobile Communication Studies}

This study investigates methodological trends in mobile communication studies.

The articles published over the past twenty years in five journals

(Communication Research, Journal of Communication, Journal of Computer-

Mediated Communication, New Media \& Society, Information, Communication

and Society) are analysed. The results show that the quantitative and qualitative

studies have increased while theoretical accounts have remained few. The

quantitative approach is the most applied. The studied articles reflect a structural

problem of science communication that stems from the lack of cumulatively of

scientific results and cross-national analyses and from the standard length of

articles that poses limitations for scientific communication.

Keywords: Mobile communication, methodology, trends, theory

\section{Introduction}

The field of mobile communication studies has been developing and maturing for the last twenty years. To defend the originality of this field, scholars have presented some distinctive characteristics, such as the affordance of mobility (Campbell, 2013) and the scope to which mobile media integrates communication in everyday life (Jensen, 2013), which distinguishes it from other fields of communication studies. However, so far mobile communication studies have been published in many different journals with the consequence that this trend has led to the dispersion of research findings. Yet the dispersion has yielded positive consequences as well. One of them is that the study of mobile communication has not been limited to a few journals confined to certain disciplines. The journals that have accepted mobile communication studies represent a large variety of scientific disciplines (e.g., communication, sociology, political science, and information technology); they have different scopes and apply different methodological approaches and preferences in what they publish (e.g., quantitative vs. 
qualitative).

The present study investigates, with a special focus on methodological trends, how mobile communication articles published over the past twenty years shape scientific communication in this particular field of research. Original research articles published in five journals are analysed. The journals that are investigated are: New Media and Society (NM\&S) (all volumes, 1999-2012); Information, Communication and Society (iCS, all volumes, 1998-2012); Journal of Computer-Mediated Communication (JCMC, all volumes, 1995-2012); Communication Research (CR, the volumes of the last 20 years, 1992-2012); and Journal of Communication (JoC, the volumes of the last 20 years 1992-2012) (more about the selection of these journals later). Apart from identifying methodological trends, the study will also critically discuss the possibility to build and advance theories on mobile communication in journal articles. Much of this theory development has taken place in monographs and edited collections (e.g., Katz \& Aakhus, 2002; Fortunati, Katz, \& Riccini, 2003; Katz, 2008; Goggin, 2010).

The approach of this study is by no means completely new as up to now a legion of studies has been carried out to analyse methodological trends in social and human science journals (e.g., Räsänen, Erola, \& Härkänen, 2005; Platt, 2006; Erola \& Räsänen, 2007; Alasuutari, Bickman, \& Grannen, 2008; Alasuutari, 2010). Previous studies have dealt, for example, with the impact of communication studies articles by investigating citation practices (e.g., Barnett, Huh, Kim, \& Park, 2011; Park \& Leydesdorff, 2009). However, these studies have not seriously tackled the issue of how methodological choices affect scientific reasoning and theory building. Furthermore, none of these studies, nor others to our knowledge, has focused on the methodological trends in mobile communication studies in particular. 
The overall aim of this study is further divided into three more specific aims. First, the study aims to find out whether quantitative or qualitative studies have been dominating the field during the last twenty years, and what has been the role of 'mixed method' and 'theoretical contributions.' By answering these questions it is possible to clarify further whether we really are living in a time of methodological pluralism, as previously queried and challenged (Payne, Williams, \& Chamberlain, 2004). It is well known that a virtuous circle between qualitative and quantitative studies should be developed.

Although positivism has historically represented a distinctive trait of sociological studies, over time scholars had to admit that not all is easily measurable. The immaterial and intangible parts of reality are, for example, difficultly captured through quantitative approaches. Hence, it has been necessary to develop qualitative studies in order to investigate these other dimensions. Quantitative and qualitative studies not only are both necessary but should nourish each other with the aim to restore a sense of completeness of the understanding of reality.

However, even today publishing mixed methods articles has turned out not to be an easy task (Creswell \& Tashakkori, 2007). Thus, in practice methodological pluralism may allow the use of diverse methods but not the mixing of qualitative and quantitative approaches. Second, the study aims to discover the methodological limitations of the published articles. This is done by analysing the methodological choices made by authors, the limitations stemming from the research design (target groups/study, object, sampling, geographical coverage, etc.), and the limitations that are reported by authors.

Through this approach, the present study aims to show how the detected methodological trends are connected to the wider aims of theory building and scientific 
reasoning in the field of mobile communication studies. It is no coincidence that theorisation is implicated in methodology just as methodology is implicated in theoretical building. It is not possible, in fact, to analyse methodology without looking at the theory that inspires it, and vice versa. In particular, the debate on theory construction has had the function, from the 1950s onwards, to coordinate and integrate in a systematic framework many methodological questions that had been treated previously in an isolated way (Gallino, 1993, p. 454). However, the fact that methodology and sociological theory developed as separate fields has made it more complicated to keep theory and methodology inside the same framework. The ambition of this study is instead - as mentioned above - to investigate the relationships between the trends of applied methodologies, theory, and scientific reasoning. In so doing, we are able to clarify the extent to which the recent surge of mobile communication studies has advanced theoretical thinking and scientific communication. The term of methodology means 'the philosophy of the research process' including the logicalepistemological assumptions and the values that provide a rationale of the study. It also refers to the criteria and the strategies researchers apply to the selection of data collection and to the interpretation of the research material. Scott and Marshall (2005, p. 406) summarize the crux of methodology as 'the study of how, in practice, sociologists and others go about their work, how they conduct investigations and assess evidence, how they decide what is true and false.' Research technique, in its turn, refers to the practical methods of collection and data analysis (Alford, 1998; Bailey, 1994, pp. 3435; see also Lazarsfield \& Rosenberg, 1955).

The rest of the article is structured as follows. First, an overview of previous studies analysing the methodological tendencies in the fields neighbouring mobile communications studies will be provided to lay a solid foundation for the article. 
Second, previous studies are explored to understand how scientific knowledge is produced and accumulated in scientific journals. After this, research material and method applied in this study will be presented. The article will then proceed to the presentation of results. Finally, the article will end by discussing the results and drawing conclusions to rationalize the knowledge produced in this field of research. This last section will also discuss the main open issues in mobile communication studies concerning science production.

\section{Previous literature}

\section{The Grand Debate About Quantitative and Qualitative Methodology and Beyond}

For the founders of the discipline the main objective of sociology was to build the critical awareness of society by developing speculative thinking and theoretical interpretation of social phenomena, processes, and change. In order to do so, sociology had to develop the capability to understand macro-level changes such as inequalities related to the industrialization of the economy and urbanizations, and to express new reflections on democracy and political rights (e.g., Calhoun, 2002). In this context the theme of 'measurement' became relevant from the very beginning. Later, the development of qualitative methods allowed the investigation of micro-aspects of social life. Qualitative methods made possible more detailed sociological descriptions and made large-scale social phenomena and changes more comprehensible (e.g., Cicourel, 1981; Collins, 2008; Goffman, 1961). With the rise of qualitative research methods in the 1960s (Alasuutari, 2010), sociologists extended their interest also to the different aspects of everyday life that escaped quantitative investigations. Sociologists in general, 
but communication sociologists in particular, began to investigate how social interaction and situational phenomena were shaping society, groups and individuals. The methodological field became more and more pluralist by overcoming the hegemony of the long-standing positivist approach (Payne et al., 2004).

Within the field of mobile communication studies, devices like the mobile phone have been situated both in relation to the sociology of change (Chirot, 1994) (the macro level) and everyday sociality (the micro level) (McGuigan, 2005). Especially microlevel studies on mobile phones show that this device contributes remarkably to shaping our everyday life (e.g., Ling, 2004, 2008; Ling \& Haddon, 2001; Oksman \& Rautianen, 2002; Poster, 2003). The macro-level analyses, on the other hand, have revealed many national differences, as well as digital gaps in adoption and usage (e.g., Castells, 2007; Authors, in press). Both qualitative and quantitative research techniques have been employed to study mobile communication at the micro- and macro-levels.

Because of the futile break between the micro-qualitative and the macroquantitative, mobile communication researchers have difficulties providing living space for a virtuous circle of the qualitative and quantitative approaches in which one will not discredit the other. As, for instance, Bryman (1992) and Greene (2007) have observed, this grand debate on quantitative vs. qualitative relates to philosophical, epistemological, and methodological issues. For post-positivist quantitative researchers, the social world exists independently from our knowledge of it. For qualitative researchers, the social world is not given but constructed or co-constructed and, thus, it needs to be interpreted rather than measured and modelled like the natural world. From the methodological perspective, the question is whether post-positivist research requires quantitative methods, and whether constructivist beliefs justify the use of qualitative methods (Greene, 2007, pp. 36-41). 
For Alasuutari, the friction between quantitative and qualitative approaches has clearly been more a characteristic of social research than humanities disciplines, which from early on have focused on actors' perspective and utilized a case-study method. In fact, he argues that even the distinction between 'qualitative' and 'quantitative' has been rather useless in many traditional humanities disciplines, in which statistical accounts have never played a substantial role. Neither has the research ever been considered to serve policy-making to the same extent as in social sciences (Alasuutari, 2010, pp. 141143). By contrast, from a long historical perspective, social science appears a strategic vehicle of governance. From this perspective, the quantitative studies have clearly served the needs of 'biopower,' to borrow Foucault's term (1976, p. 140), or of 'the state-centred resource management of the Keynesian era’ (Alasuutari, 2010, p. 151).

An amplified interest in the mixing of different modes of inquiries during the past two to three decades (Alasuutari, 2010; Alasuutari, Bickman, \& Grannen, 2008; Ragin, 1987) is a sign of willingness to transcend the unproductive competition between the two camps in social science. The intention of the mixed method approach is to combine the saving graces of both quantitative and qualitative methods. The Journal of Mixed Methods Research launched in 2007 can be considered a hallmark in advocating the triangulation of methods. The rationale behind the triangulation has typically been that of either 'convergence’/‘cross-validation’ or 'complementary’ (e.g., Erzberger \& Prain, 1997, pp. 143-145; Sale, Lohfeld, \& Brazil, 2002, p. 48). While the former is premised on an idea that different methods produce more consistent results of the same undefined reality (Silverman, 1985, p. 105), the latter views that different methods are used to investigate different aspects or different levels of reality. 


\section{Methodological Trends in Journal Publishing: What Happens to the Theoretical?}

Many scholars in different countries have paid attention to the balance of power between different research approaches. In Alasuutari's (2010) meta-analysis on studies about methodological trends, it is argued that the rise of qualitative studies has not occurred at the expense of quantitative articles. Studies dealing with publishing in various countries, such as Finland (Erola \& Räsänen, 2007; Räsänen et al., 2005), Canada, and U.S. (Platt, 2006, pp. 218-219), have not shown any dramatic dip in the proportion of quantitative articles published in major social science journals between the 1950/60s and 2000s. As regards new media studies, Peng, Zhang, Zhong and Zhu (2012) show that the articles that deal with the Internet and were published in social science journals between 2000 and 2009 employ most often quantitative approach (59\%). Qualitative studies made up 19 per cent and theoretical studies only 5 per cent of all studied articles. The remainder (17 \%) consists of reviews and other studies that do not fall into these categories. On the whole, social sciences have become more and more empirical with the majority of their expansion in qualitative inquiry. Peng et al.'s study indicates that new media articles are likely to follow the same overall trend. It has been argued that the biggest loser of this ‘empiricalisation’ of social research is theoretical research (Alasuutari, 2010, p. 144; Bechhofer, 1996). This study builds upon a broad definition of theoretical research, and encompasses approaches ranging from general social theories to the discussions and systematisation of new ideas and concepts, and to those studies that do not include primary data or analysis. The reason for the broad definition proposed here is that we want to include in the 'theoretical research' the studies which are grounded in different scientific traditions with different understanding of the boundary between the theoretical and the empirical. 
In German sociology, for example, there has been a distinctive division between 'non-empirical' general theories that aspire to describe and interpret how the social, the society, and the cultural are constituted, and research theories that utilize empirical evidence to theorize social phenomena (Noro, 2000). Cameralism especially contributed to the rise of empirical evidence based on research theories that could be used to maximize the success of the national economy. Later, the German scholarly system had a deeper cultural impact on the United States than on many other European countries (Bhattacharya, 2012, pp. 216-219). More recently, in German sociology the concept Zeitdiagnose (the diagnosis of contemporary time) has been introduced as a new category that falls in between general and research theories. According to ReeseSchäferk (1996), the rationality of Zeitdiagnose studies (which aim to describe 'who we are today') is based on the plausibility, solidity, and consistency of research, as well on its capacity to provoke new insight in the readers. In American sociology, Robert Merton's (1949/2007, p. 448) notion of middle range theory similarly tried to bridge the gap between the limited hypotheses of empirical studies and grand theory studies, by emphasizing theoretical approaches 'that lie between the minor but necessary working hypotheses ... and the all-inclusive systematic efforts to develop a unified theory that will explain all the observed uniformities of social behavior, social organization, and social change.’

The other tradition shaped in Mediterranean countries, such Italy, France, and Spain, as well as the United Kingdom, has evolved around the idea of theory as the transmission, discussion, and systemization of theoretical ideas. The focus has been on the interpretation of the social meaning of the studied phenomenon. In this sense, they also belong to the oldest branches of sociology (Horkheimer \& Adorno, 1956) that have lost ground as regards the advancing of empirical sociology. Robert Mertons’ phrases 
'general orientations' and 'conceptual analysis,' albeit representative of American social theory, are illustrative in this regard. With some variance they correspond, as Gallino reports (1993, p. 445), to Dahrendorf's notion of metatheories (1963), to Friedrichs' notion of paradigms, to Gouldner's notion of domain assumptions (1970), and to Rose’s notion of reality images (1967).

As to journal publishing, in this study it is considered important to understand how journal articles integrate theory and empirical research (methods). This is also the key idea in Merton's (1945) thinking as he proposes that a true sociological theory exists only when concepts are connected to one another through empirically observed relations. This is because he found that theoretical studies were usually aimed at discovering the types of variables that should be taken into consideration, but without understanding the relations between variables.

\section{What is Published in Journals?}

It remains to be discussed what kind of an arena are journals for publishing empirical and theoretical research on mobile communication. In their meta-analysis of citing books and journals, Huang and Chang (2008, pp. 1822-1824) show that compared with natural science, humanities scholars and social scientists tend to cite more books than other sources. They also show evidence for the increasing publishing of journal articles in some disciplines of social science and humanities that are aligned towards with the methods of natural sciences (Huang \& Chang, 2008, p. 821). Apart from the benefits related to the analysis of citation practices, some concerns have been raised concerning its relevance. Citing is not only based on the pure merits of the cited publications; studies are citied also to disagree with the author and for the purpose of revealing mistakes in previous literature. Gratuitous (e.g., some studies 'must' be cited) and raw 
citing (with loose or no connection with the topic) also takes place in academia (Rice, Borgman, \& Reeves, 1988, p. 257). With this in mind, it is unsurprising that some studies have found support for the Matthew effect in citation practices (e.g., Stewart, 1983). Recognized scholars are cited more than those who have presented the same or similar findings but who are less experienced.

It may also be asked if journal publishing favours some types of studies over others. One of the major concerns in this respect relates to the balance between empirical and theoretical research. Some studies hint that journals with strict length limitations for articles do not provide enough space for developing innovative theories and concepts (Oxley, Rivkin, Ryall, \& Strategy Research Initiative, 2010, p. 382), and would thus be more suitable for publishing well-outlined and focused empirical studies. Furthermore, previous studies show that the 'old world' (Europe) has not succeeded in being published, for instance, in top information system journals when compared with their American counterparts (Lyytinen, Baskerville, Iivari, \& Te’eni, 2007). In addition, it has been argued that the space of publishing social science research is especially limited to English-speaking countries (Paasi, 2005). With regard to gender differences, literature indicates that female scholars' contributions are cited less than those written by men. This phenomenon is known also as the Matilda effect (Knobloch-Westerwick \& Glynn, 2012).

\section{Research Materials and Methods}

\section{Research Material}

The five communication and media studies journals were selected to keep the size of the research material manageable for an inquiry that utilized both qualitative and quantitative methods. Multiple criteria were applied to the selection of the journals. 
First, as the study deals with mobile communication in particular, two journals were chosen that according to previous literature (Barnett et al., 2011; Park \& Leydesdorff, 2009) are the most influential in the field of communication studies: Communication Research (CR, the volumes of the last 20 years, 1992-2012); and Journal of Communication (JoC, the volumes of the last 20 years 1992-2012). Second, the Journal of Computer-Mediated Communication (JCMC, all volumes, 1995-2012) was included in the study owing to its particular focus on computer-mediated technologies, which as we know are progressively more transportable. Third, two journals that focus on the relationship between communication/media and society were used in the analysis: New Media and Society (NM\&S, all volumes, 1999-2012) and Information, Communication and Society (iCS, all volumes, 1998-2012). Considering their aims and scope, it was expected that these journals would publish more articles that take into account the impact of communications on all sorts of mobility in society (e.g., Urry, 2007). Fourth, having worked in the field of mobile phone research for several years, the authors of this article considered these journals to welcome submissions dealing with mobile communication studies, and whose readership expect to find articles on mobile communication. Lastly, bibliometrics were consulted to justify the selection of journals. As Table 1 shows, all five journals were ranked in the 2011 ISI Journal Citation Reports: JoC was ranked 3/72 in Communication with Impact Factor (IF) 2.452; JCMC was 5/72 with IF 2.172; CR was 7/73 with IF 2.014; NM\&S was 16/72 with IF 1.394; and iCS was 39/72 with IF 0.700. The h5 index and the SJR indicators, however, present different rankings, which confirms that none of these indicators alone should be used as a criterion for selecting journals in a more detailed analysis. Despite all this, it is worth noticing that these journals, most of them with an American editorial desk, are particularly influential in US. This fact might be reflected in the results of this study. 
Articles were chosen manually by going through the titles of all original research articles published in these journals during the past 20 years. Editorials, review articles, book reviews and alike were excluded. The articles which according to the title dealt with mobile phone or mobile communication were selected. If unsure, the abstract was consulted. The data gathered consists of 66 articles, which represent the five journals as follows: New Media and Society (N=40); Journal of Computer-Mediated Communication ( $\mathrm{N}=12)$; Information, Communication and Society $(\mathrm{N}=10)$; Journal of Communication ( $\mathrm{N}=3$ ); and Communication Research $(\mathrm{N}=1)$. Much information from each article was recorded for analytical purposes. The recorded data includes: name of the article (with the year of publication and issue); authors' names and affiliations; first author's gender; first author's country of residence; methodological approach (theoretical/quantitative/qualitative/mixed); research method; sample size (if relevant); target group; country coverage (single country/country comparison); methodological suggestions and limitations reported by author(s).

\section{Method}

The articles were analysed by applying a systematic procedure devised to examine the content of recorded material, the method that is also known as content analysis (Krippendorff, 2004). Both quantification and qualitative content analysis were employed. Whereas the former was employed to reveal the methodological trends over time, the latter was applied to analyse methodological limitations reported by authors and the need for future research. The chosen perspective to mobile communication, the sociology of communication, is partly accountable for the interpretation of the discovered methodological trends. It is in place to remind that by analysing the same 
research material, for instance, through the lens of cultural studies on mobile communication or (social)psychology, the attention would be directed to slightly different methodological strengths and defects (e.g. lack of ethnographic research and micro vs. macro level analysis, respectively).

\section{Results}

\section{The Dominance of Empirical Research: Toward Quantitative Studies?}

The analysis is based on 66 articles that were published between the years 1999 and 2012. No articles on mobile communication were published between 1992 and 1998 in the five journals studied. Considering that the diffusion of the mobile phone accelerated in the mid-1990s, this means that scholars studying the social aspects of this technology privileged other forms of publication outlets, such as books and article collections (e.g., Katz, \& Aakhus, 2002). The monographs and edited volumes have remained as important publication outlets until today (e.g., Fortunati, Katz \& Riccini, 2003; Ling, 2004, 2008; Katz, 2008; Goggin, 2010). The journals that were studied did not publish on mobile communication in their 2000 and 2001 volumes either. The first article in our sample was published in 1999 and it was about the mobile phone have-nots (Leung \& Wei, 1999). The topic of the first article, have-nots instead of haves, indicates that scholars anticipated the irreversible breakthrough of mobile phones as early as the end of the 1990s.

Since 2002, mobile phone and communication studies have been published 
every year. Figure $1^{1}$ shows the relative proportions of mobile communication studies in all original research articles published in these five journals in two-year intervals. 1 The figure illustrates that research on mobile communication truly proliferated in the middle of the first decade of the 21st century. By 2007-2008, the share of these studies stabilized between 3.5 and 4.0 per cent of all the published articles.

\section{-- Insert Figure 1 here --}

Figure 2 presents the absolute number of mobile communication studies broken down into qualitative, quantitative, theoretical (defined as described above) and mixed method articles, published between 1999 and 2012. First, it can be discovered that a rather good balance between quantitative and qualitative articles has been sustained over the years. While the number of both qualitative and quantitative inquiries has steadily risen, their relative shares have remained almost the same: fifty-fifty. The overall number of quantitative studies (27) slightly exceeds the qualitative ones (23). What is a more eyecatching feature is that the relative proportion of theoretical/non-empirical (review) studies has declined. During the twenty years studied, only 12 theoretical inquiries were published, meaning, on average, less than one study per year ${ }^{2}$. However, it might be that

\footnotetext{
${ }^{1}$ In this and other graphs, figures are presented in two-year intervals in order to guarantee a sufficient number of articles in each category.

2 The additional analysis of citations, based on data obtained by March 27, 2013 from the Google Scholar service, was executed. Results show that although the average number of citations for quantitative articles (Mean $(M)=42.5$, Median $(M n d)=$.22 ) is higher when compared with qualitative ( $M=42.5$, Mnd.=22), theoretical $(M=22.2$, Mnd.=7), and mixed method $(M=15$, Mnd.=13) studies, the Kruskall-Wallis test ( $\mathrm{p}=.331)$ applied to the medians of the citations confirms that these differences are statistically not significant.
} 
by including newer journals, such as Convergence (1995-) First Monday (1996-), the Fiberculture Journal (2003-), or Wi (2007-), more theoretical and qualitative methods would have occurred. There is also a new journal devoted to 'Mobile Media and Communication', which could not be included in the analysis as it was launched only 2013. Figure 2 also reveals that mixed-method studies have been very rare. Only four (4) mixed method studies were published, all of them in 2008 or later.

\section{-- Insert Figure 2 here --}

In addition to the methodological approach, attention is also paid to the origin of the research material. What is startling is the small number of cross-national studies. Of all 66 articles, only five (5) were grounded on a cross-national research design. The number of countries that were represented in these studies varied between two and three. Typically at least the US or Japan was included in these comparative designs, but also Sweden, Spain, and Czech Republic were included in cross-national accounts. The rest - 61 articles - were single country studies. Taking into account both cross-national and single country studies, US samples were used in 15 articles. This makes the US clearly the most studied country in mobile communication studies.

$$
\text { --Insert Figure } 3 \text { here -- }
$$

As to the authors, the data used in this study indicates that men are more numerous than women when the first author's gender is considered. Figure 1 shows that in around 2007-2008, female authors, however, began to increase their relative proportion of all 
authors $^{3}$. In Table 2 the first author's country of affiliation is presented according to continent. It shows that scholars from North America - and more generally from English speaking countries, such as the US, Canada, Australia and the UK (37 articles in total) - are most numerous in the sample. The old world, Europe, comes second place after North America, and Asia holds third place with a good number of publications. In contrast to these three continents, only one paper from Africa - and no studies from South America or Latin America - was published ${ }^{4}$. If the figures were presented proportionately to the number of mobile communication scholars in each country, the numbers would probably be more favourable to Europe and Scandinavian countries in particular.

-- Insert Table 2 here -

\section{The Analysis of Methodological Limitations}

Of all the articles studied, 49 are based on empirical data that is clearly definable. The rest of the papers are theoretical studies or empirical studies utilizing very selective and indefinable data (such as Zeitdiagnosis type of studies). One of the most striking methodological limitations that emerges from the data is the use of college or other students as research objects. Ten out of these 49 are based on convenience samples of university students. In addition, seven articles analyse teenagers or youth, and six out of

3 The citation analysis also shows no significant differences between the male $(M=33.1$, Mnd.=17) and female (M=33.0, Mnd.=11) first authors with regard to the received citations ( $\mathrm{p}=.794$, Mann-Withney)

4 The citation analysis did not reveal cross-continental differences between North America ( $M=36.0$, Mnd.=16), Europe (M=25.1, Mnd.=12) and Asia (M=53.0, Mnd.=24) with regard to the received citations either $(\mathrm{p}=.539$, Kruskall-Wallis). 
these seven studies are based on some sort of convenience sample. As to the national level representative surveys, only five studies apply either random sampling or some sort of stratified (quota) sampling of entire population. Only two studies are based on traffic data from telecom operators. A large majority of all empirical studies are grounded on some sort of convenience samples or a case study design; research materials are collected from single organizations, NGOs, or from some online and offline communities.

Many authors recognize and report the limitations of their own accounts as the conventions of academic writing and reporting require. However, these limitations are typically reported in a mechanic way, and more in quantitative than in qualitative studies. The problems caused by small and convenience samples, which reduce the generalizability of the results, are commonly reported. The need for cross-national approaches is also recognized by authors themselves (in seven studies, authors mention the explicit need, or underline the chosen one-country approach as a limitation). In six papers, authors also raise the need of longitudinal or repeated cross-sectional studies. The one study even argued that as mobile technologies, services, and content develop so quickly, even a two-year time interval in repeated surveys can sometimes be too long to detect changes over time. The fast technological development is also related to the problems in the operationalization of research objects as it was pointed out in two articles. It is difficult to develop measurement instruments that would be robust and sustainable over time when a research object is continuously in motion.

Lastly, as of 2006, articles have called for more nationally representative samples, and more cross-national and longitudinal studies. The same needs were reiterated in articles published in 2011 and 2012. The data recorded from 66 articles does not indicate that authors would systematically build upon the results of previous 
studies as similar needs for further studies are reported over and over again.

\section{Discussion and Conclusive Remarks}

The presence of articles on mobile communication in the studied journals is under 4 per cent. This result confirms the great dispersion of this type of study. In response to the

first aim of our research, this study reveals that the quantitative approaches are the most applied, followed by qualitative. Only a few multi-method approaches and theoretical studies were included in the sample. This means that a neopositivist approach still prevails in the field of studies on mobile communication, and maintains the conceptualisation of reality as an object that researchers can and have to measure in order to understand the social phenomena and processes connected to their research topic. In these respects, the results of our study are in line with previous findings of Peng et al. (2012) dealing with methodologies applied in Internet studies.

At the same time the modest presence of theoretical papers entails the quasidisappearance of the grand theory, which would be required to make mobile communication studies resonate with the fundamental categories of sociology. If theory construction passes through the activation of these categories and the systematisation of all the pieces of knowledge produced in a unique framework, as proposed for instance by Merton, very little of this is present in the selected articles. And this is a serious problem of science production for these studies.

To summarize, the methodological trends in the field of mobile communication shape the theoretical directions of the field towards a scant positivism, a descriptive phenomenology, the restricted cumulativity of science and the lack of a grand 
sociological theory. These theoretical directions bring sociological discourse exactly to the opposite side of what it should be: the critical conscience of society. The field of mobile communication studies is not different from the other fields of contemporary sociology. Compared to the past, present sociologists are less able to inspire social criticism, conflicts, and movements. If anything, the discovered theoretical directions serve the development of their personal academic careers.

The comparisons over time show other problems of science production and communication. First, journal publishing has not objectively promoted theory building and scientific reasoning, although it is a common fact that high-level journals also require in principle that empirical studies make contributions to theory. Second, it is the format of journals itself and their specific mission that, in a certain sense, discourage theory construction. The only trace of theory that can be found in articles of standard length (about 7,000 words) is usually one that represents itself as a 'fiction of hypotheses’ to borrow again Horkeimer's and Adorno’s expression. Third, these findings indicate that the structure of scientific publishing which characterizes journal articles encourages authors to apply a single method.

It also emerges from the present study that mobile communication research mirrors the tendency to investigate objects extracted from their context and strictly isolated from large social contexts. According to this practice, mobile communication research continues to weight the idea of a 'value-free sociology' expressed by Max Weber (1949/2012) and criticized by others (e.g., Gouldner, 1962). Weber’s suggestion to researchers to refrain from judging during the research process was beneficial for the avoidance of that subjectivity of the investigator which could pollute the collection and interpretation of data. However, this idea becomes a problem when the suspension of the evaluation entails the complete disappearance of judgment and of criticism at any 
stage of the sociological inquiry. As a consequence, a loss of comprehension of the role of mobile phone communication inside the structure and processes that regulate society has occurred. The loss is compounded by the other characteristics of these studies: the fact that they are monocultural and the fact that they centre around the US and Europe, which impose other serious problems of science production. Hence, if one asks how this new production of research on mobile communication lies in the panorama of social research, the answer is that these studies are rarely able to deal with the categories and concepts that are at the basis of sociology as a discipline, for the reasons detailed above.

The study also supports the idea of the 'empiricalisation' of research proposed by Alasuutari and others. The number of empirical studies, both quantitative and qualitative (but not mixed methods), has increased, while theoretical accounts have remained few. The impression is that now a new wave of ingenuous empiricism has developed like that observed by Dewey in the beginning of 20th century (1939). Dewey described social research with scientific claims as if it was based on the idea that facts are at hand and that it is sufficient only to observe carefully and bring them together in sufficient numbers to ensure their generalization. In particular, the quantitative part of these empirical studies continues to exhibit the same characteristics detected by Horkheimer and Adorno in 1956. The quantitative studies on mobile communication respond to the need of sociological research based on the criteria of accuracy and objectivity, and which hence aims to pursue the verifiability and falsifiability of statements as well as the quantifiability and repeatability of data. However, the element of social criticism continues to be excised from these quantitative studies. In this way, it happens that sociology loses its main mission, that is, to have a critical awareness of society. This problem is related to both science production and science communication since the identity of the discipline has changed in practice without that this has been 
clarified in the premises of the discipline itself.

In response to the second aim of this study, the most obvious methodological limitations relate to the use of convenience and one-country samples, as well as to the use of students as the target group, that can be viewed as problems typical of social science production. It is tempting to argue that these limitations stem also from continuously diminishing financial resources in universities. These sampling methods and target groups are in fact more compatible with an ever smaller financial investment in research projects, which have forced researchers toward less expensive empirical research designs. This can easily create a rebound on many universities and scholars, who may shy away from large-scale and representative research projects and consequently become incapable of conducting them.

The results of the present study also prompt us to ask whether the reporting of methodological limitations and of the needs for future research is a pure formality. The mention of the need for larger and more representative studies can be considered as an easy way to fulfil the requirement of self-criticism in scientific articles. As the same needs are also repeated over and over again, it may be asked if the scientific communication that takes place via journals is really good for promoting the cumulativity of science (Westlund, 2002). If the new studies do not take seriously the limitations reported earlier, or if there is a lack of resources that prevents a response to these limitations, it may be asked whether science production, communication and sharing can develop in a rational way, and thus it becomes difficult to understand how science advances. Theories are usually built upon empirical research, first, to explain the theories; second, to verify whether the interpretations of the results and the new ideas that emerge are correct; and third, to verify if these ideas should not be updated or if they should be revised in the light of social change. But if the empirical results are not 
situated (also presented) in an organic way in a cumulative framework, theory building becomes almost impossible. All limitations reported above are not independent of external factors. What ends up being published in these journals is influenced by the political economy of journals: largely volunteer editorial labour, generic conventions, and tenure and promotion evaluations have a lot to do with what ends up being published. The structural pressures of tenure and promotion evaluations that call for efficient publishing can be taken as an example. It is easier to meet the set requirements, for example, with relatively small convenience samples of college students, who are easily accessible for many academic scholars, than large cross-national data sets that require lots of time and financial resources. The political economy of journals, which makes many authors to pay for language editing proofreading services, and in some case, for submitting and publishing, affects what is published as well. The premises for journal publishing are better for scholars representing wealthy countries, research institution and universities. The small number of articles published by Asian and African scholars is an indicator of this external effect.

To conclude, the present study provides a self-reflection on the methodology applied in mobile communication studies. The study proposes a heuristic model of investigation of the methodological trends characterizing this field of research and shows how these trends affect the production of scientific knowledge and science communication in the same field. The main empirical results that emerged from this study are that quantitative approaches are the most applied in the articles studied, but that the methodological limitations they present are serious, since the samples used are mainly convenience (with students as the target groups) and one-country samples. Thus, the results reflect a structural problem of science production and communication that stems, for example, from the lack of accumulation of scientific results and cross- 
national analyses, and from the standard length of articles which poses evident limitations. To promote the virtuous circle of the qualitative and quantitative approaches researches should be encouraged to move, more than they do today, from one methodological camp to another. In their author guidelines journals could, for instance, provide a recommended article structure for mixed methods (and theoretical) manuscripts separately. Current guidelines are typically made for single method empirical studies.

Finally, at least two best practices aimed to improve the knowledge management strategies and science communication can be suggested for future research. The first is the suggestion to report within in-text citations not only the name of author(s) and year, but also the dimensions of the sample used in the cited study. This should better maintain the scope of the related research through the exercise of referring to earlier studies. Second, every journal in the last number of each volume, or in the first number of the next volume, should summarize the main results of the research published in the previous year, in order to assist the reader to grasp quickly the fundamental implications of earlier research.

\section{Acknowledgements}

To be added after refereeing process

\section{References}

Alasuutari, P. (2010). The rise and relevance of qualitative research. International Journal of Social Research Methodology, 13, 139-155. doi: $10.1080 / 13645570902966056$ 
Alasuutari, P., Bickman, L., \& Brannen, J. (2008). Introduction: Social research in changing social conditions. In P. Alasuutari, L. Bickman \& J. Brannen (Eds.), The SAGE handbook on social research methods (pp. 1-8). London: Sage.

Alford, R.R. (1998). The craft of inquiry: Theories, methods, evidence. New York: Oxford University Press.

Bailey, K.D. (1994). Methods of social research (4th ed.). New York: The Free Press.

Barnett, G. A., Huh, C., Kim, Y., \& Park, H. W. (2011). Citations among communication journals and other disciplines: A network analysis. Scientometrics, 88, 449-469. doi: 10.1007/s11192-011-0381-2

Bechhofer, F. (1996). Quantitative research in British sociology: Has it changed since 1981? Sociology, 30, 583-591. doi: 10.1177/0038038596030003010

Bhattacharya, N. (2012). The evolution of knowledge in the university. The Information Society, 28, 208-227. doi: 10.1080/01972243.2012.689607

Bryman, A. (1992). Quantity and quality in social research. London: Routledge.

Calhoun, C. J., Gerteis, J., Moody, J., \& Pfaff, S. (Eds.) (2007). Classical sociological theory (2nd ed.). Malden: Blackwell.

Campbell, S. (2013). Mobile media and communication: A new field, or just a new journal? Mobile Media \& Communication, 1, 8-13. doi: $10.1177 / 2050157912459495$

Castells, M., Fernández-Ardèvol, M., Qiu, J. L., \& Sey, A. (2007). Mobile communication and society: A global perspective. Cambridge: MIT Press.

Chirot, D. (1994). How societies change. Thousand Oaks: Pine Forge Press.

Cicourel, A.V. (1981). Notes on the integration of micro- and macro-levels of analysis. In K. Knorr-Cetina \& A.V. Cicourel (Eds.), Analysis in social theory and 
methodology: Toward an integration of micro- and macro-sociologies (pp. 5180). Boston, MA: Routledge and Kegan Paul.

Collins, R. (2008). Violence: A micro-sociological theory. Princeton: Princeton University Press.

Creswell, J. W. \& Tashakkori, A. (2007). Editorial: Developing publishable mixed methods manuscripts. Journal of Mixed Methods Research, 1, 107-111. doi: $10.1177 / 1558689806298644$

Dahrendorf, R. (1963). Die angewandte Aufklärung: Gesellschaft und Soziologie in Amerika [The applied Enlightment: Society and Sociology in America]. München: Piper.

Erola, J. \& Räsänen, P. (2007). Suomalaisen sosiaalitieteen menetelmätrendit 1990- ja 2000-luvuilla [Methodological trends in Finnish social sciences during 1990s and 2000s.]. Janus, 15, 297-315.

Erzberger, C. \& Prein, G. (1997). Triangulation: Validity and empirically-based hypothesis construction. Quality \& Quantity, 31, 141-154. doi: 10.1023/A:1004249313062

Fortunati, L. Katz, J. \& Riccini, R. (eds.) (2003). Mediating the Human Body: Technology, Communication and Fashion. Mahwah, New Jersey: Erlbaum.

Fortunati, L. \& Taipale, S. (2014, in press) The advanced use of mobile phones in five European countries. British Journal of Sociology.

Foucault, M. (1976). The history of sexuality Vol. 1: An introduction. New York: Vintage Books.

Friedrichs, R.W. (1970). A sociology of sociology. New York: Free Press.

Gallino, L. (1993). Dizionario di Sociologia [Dictionary of Sociology]. Torino: UTET. 
Goffmann, E. (1961). Encounters: Two studies in the sociology of interaction. Indianapolis: Bobbs- Merrill.

Google Scholar (2013) Google Scholar Metrics. Retrieved March 19, 2013, from http://scholar.google.com/intl/en/scholar/metrics.html\#metrics

Gouldner, A.W. (1970). The coming crisis of western sociology. New York: Basic Books.

Gouldner, A. W. (1962) Anti-minotaur: The myth of a value-free sociology. Social Problems, 9, 199-213.

Greene, J. C. (2007). Mixed methods in social inquiry. San Francisco: John Wiley \& Sons.

Goggin. G. (2010). Global mobile media. New York: Routledge.

Horkheimer, M. \& Adorno, T. W. (1956). Soziologische Exkurse [Sociological Excursions] Frankfurt am Main: Europäische Verlagsanst.

Huang, M.-H. \& Chang, Y.-W. (2008). Characteristics of research output in social sciences and humanities: From a research evaluations perspective. The Journal of the American Society for Information Science and Technology, 29, 1819-1828. doi: 10.1002/asi.20885

Jensen, K. B. (2013). What's mobile in mobile communication? Mobile Media \& Communication January, 1, 26-31. doi:10.1177/2050157912459493

Katz, J. E. (Eds.) (2008). Handbook of Mobile Communication Studies. Cambridge, MA: MIT Press.

Katz, J. E. \& Aakhus, M. A. (Eds.) (2002). Perpetual contact: Mobile communication, private talk, public performance. Cambridge, UK: Cambridge University Press

Knobloch-Westerwick, S. \& Glynn, C.J. (2013). The Matilda effect: Role congruity effects on scholarly communication: A citation analysis of Communication 
Research and Journal of Communication articles. Communication Research, 40, 3-26. doi: 10.1177/0093650211418339

Krippendorff, K. (2004). Content analysis: An introduction to its methodology. Thousand Oaks, CA: Sage.

Lazarsfeld, P. F. \& Rosenberg, M. (Eds.) (1995). Language of social research: A reader in the methodology of social research. Glencoe: Free Press

Leung, L. \& Wei, R. (1999). Who are the mobile phone have-nots? Influences and consequences. New Media \& Society, 1, 209-226. doi:

$10.1177 / 1461444899001002003$

Ling, R. \& Haddon, L. (2001). Mobile telephony and the coordination of mobility in everyday life. In J. E. Katz (Ed.) Machines that become us: The social context of personal communication technology (pp. 245-66). New Brunswick: Transaction Publisher.

Ling, R. (2004). The mobile connection: The cell phone's impact on society. San Francisco: Morgan Kaufmann.

Ling, R. (2008). New tech, new ties: How mobile communication is reshaping social cohesion. Cambridge: The MIT Press.

Lyytinen, K., Baskerville, R. Iivari, J. \& Te'eni, D. (2007). Why the old world cannot publish? Overcoming challenges in publishing high-impact IS research. European Journal of Information Systems, 16, 317-326. doi: 10.1057/palgrave.ejis.3000695

McGuigan, J. (2005). Towards a sociology of the mobile phone. Human Technology, 1(1), 45-57.

Merton, R. (1945). Sociological Theory. American Journal of Sociology, 50(6), 462473. 
Merton, R. (1949/2007) On sociological theories of the middle range [1949]. In C. J. Calhoun , J. Gerteis, J. Moody, S. Pfaff \& I. Virk (Eds.) Classical sociological theory (pp. 448-459). Malden, MA: Blackwell.

Noro, A. (2000) Aikalaisdiagnoosi sosiologisen teorian kolmantena lajityyppinä [Diagnosis of an Era as the Third Type of Sociological Theory]. Sosiologia 37(4), 321-329.

Oksman, V., \& Rautianen, P. (2002). Perhaps it is a body part: how the mobile phone became an organic part of the everyday lives of the Finnish children and teenagers. In J. E. Katz (Ed.), Machines that become us: The social context of personal communication technology (pp. 293-308). New Brunswick: Transaction Publishers.

Oxley, J.E. Rivkin, J.W., Ryall, M. D. \& Strategy Research Initiative (2010) The strategy research initiative: Recognizing and encouraging high-quality in strategy. Strategic Organization, 8, 377-386. doi: 10.1177/1476127010387821

Paasi A. (2005). Globalisation, academic capitalism, and the uneven geographies of international journal publishing spaces. Environment and Planning A, 37, 769789. doi:10.1068/a3769

Park, H. W., \& Leydesdorff, L. (2009). Knowledge linkage structures in communication studies using citation analysis among communication journals. Scientometrics, 81(1), 157-175.

Payne, G., Williams, M., \& Chamberlain, S. (2004). Methodological pluralisms in British sociology. Sociology, 38, 153-163. doi: 10.1177/0038038504039372

Platt, J. (2006). How distinctive are Canadian research methods? Canadian Review of Sociology/Revue canadienne de sociologie, 43, 205-231. doi: 10.1111/j.1755618X.2006.tb02220.x 
Poster, M. (2003). Everyday life and mobile phones. In K. Nyíri (Ed.), Mobile democracy: Essays on society, self and politics (pp. 137-146). Vienna: Passagen.

Ragin, C.C. (1987). The comparative methods: Moving beyond quantitative and qualitative strategies. Berkeley, CA: University of California Press.

Räsänen, P.; Erola, J. \& Härkönen, J. (2005). Teoria ja tutkimus Sosiologia-lehdessä [Theory and research in Sosiologia-journal]. Sosiologia, 42(4), 309-314.

Reese-Schäfer, W. (1996). Zeitdiagnose als wissenschaftliche Aufgabe [Diagnosis of an Era as a scientific task]. Berliner Journal für Soziologie, 6(3), 377-390.

Rice, R. E., Borgman, C. L., \& Reeves, B. (1988). Citation networks of communication journals, 1977-1985: Cliques and positions, citations made and citations received. Human Communication Research, 15, 256-283. doi: 10.1111/j.14682958.1988.tb00184.x

Rose, A.M. (1967). The relation of theory and method. In L. Gross (Ed.) Sociological theory: Inquiries and paradigms (pp. 210-216). New York: Harper \& Row.

Sale, J. E., Lohfeld, L. H., \& Brazil, K. (2002). Revisiting the quantitative-qualitative debate: Implications for mixed-methods research. Quality \& Quantity, 36, 43-53.

SCImago (2013). SJR — SCImago Journal \& Country Rank. Retrieved March 19, 2013, from http://www.scimagojr.com

Scott, J. \& Marshall, S. (2005). Oxford Dictionary of Sociology. Oxford: Oxford University Press.

Silverman, D. (1985). Qualitative methodology and sociology: Describing the social world. Aldershot: Gower.

Stewart, J. A. (1983). Achievement and ascriptive processes in the recognition of scientific articles. Social Forces, 62, 166-189. doi: 10.1093/sf/62.1.166 
Thomson Reuters (2013) Introducing The Impact Factor. Retrieved March 19, 2013, from http://thomsonreuters.com/products_services/science/academic/impact_factor/. Urry, J. (2007). Mobilities. Cambridge: Polity.

Weber, M (1949/2011). Methodology of social sciences (E.S. Henry \& A. Finch, Trans.). New Brunswick, NJ: Transactions.

Westlund, O. (2012). Rich media and rich science: Web squared cumulativity conceptualization. European Review, 20, 182-194.doi:

$10.1017 / \mathrm{S} 1062798711000433$ 
Table 1. Comparison of bibliometrics of the selected journals

Table 2. Authors' affiliations by continent (N)

Figure 1. Proportion of mobile phone and communication articles of all published articles in the five journals between 1999 and 2012 (\%)

Figure 2. Published mobile communication articles by methodological approach between 1998 and $2012(\mathrm{~N})$

Figure 3. Articles by first author's gender (N) 